\title{
Authors' reply: Comment on: Efficacy of intubation performed by trainees on patients in the lateral position
}

Singapore Med J 2021; 62(7): 368 https://doi.org/10.11622/smedj.2021096

Dear Sir,

We appreciate the letter by Gaszyński ${ }^{(1)}$ and his comments and interest in our paper. ${ }^{(2)}$ Indeed, the widespread use and availability of videolaryngoscopy $(\mathrm{VL})$ has been revolutionary in the way it has improved glottic visualisation and success rates in various clinical scenarios. VL is now an integral component of our difficult airway algorithms. Furthermore, many have suggested that VL should be the new standard of care in airway management. ${ }^{(3)}$ Certainly, this seems to already be the case in many emergency departments and intensive care units.

While many anaesthesiologists would still not consider using $\mathrm{VL}$ as routine for normal airways, the role of $\mathrm{VL}$ in both predicted and unexpected difficult intubations is well documented. ${ }^{(4)} \mathrm{VL}$ has also been suggested to improve success rates and ease of intubation in novices and trainees. ${ }^{(5)}$ In a situation where the patient assumes an unconventional position such as the lateral position, VL offers many advantages: a magnified and brighter image, and a common view shared by both trainee and instructor, allowing for better guidance and instruction. This would be helpful in ensuring a successful intubation attempt.

We believe that to be well-rounded anaesthesiologists, our training should include usage of both direct laryngoscopy and alternative airway devices such as, but not limited to, videolaryngoscopes. The choice and effective use of a particular technique would depend on the clinical scenario and the experience and skillset of the clinician.

Yours sincerely,

Sin Yee $\underline{\text { Goh}}{ }^{1}$, Sze Ying Thong ${ }^{1}$, Yufan $\underline{\text { Chen }^{1}}$, Andrew Seun Kong ${ }^{1}$

${ }^{1}$ Department of Anaesthesiology, Singapore General Hospital, Singapore. gohsinyee@gmail.com

\section{References}

1. Gaszyński T. Comment on: Efficacy of intubation performed by trainees on patients in the lateral position. Singapore Med J 2021; 62:367.

2. Goh SY, Thong SY, Kong AS. Efficacy of intubation performed by trainees on patients in the lateral position. Singapore Med J 2016; 57:503-6.

3. Zaouter C, Calderon J, Hemmerling TM. Videolaryngoscopy as a new standard of care. Br J Anaesth 2015; 114:181-3.

4. Lewis SR, Butler AR, Parker J, Cook TM, Smith AF. Videolaryngoscopy versus direct laryngoscopy for adult patients requiring tracheal intubation. Cochrane Database Syst Rev 2016; 11:CD011136.

5. Howard-Quijano KJ, Huang YM, Matevosian R, Kaplan MB, Steadman RH. Video-assisted instruction improves the success rate for tracheal intubation by novices. Br J Anaesth 2008; 101:568-72. 